\title{
Peritoneal Dialysis Is Not a Superior Therapy to Hemodialysis: A Comparison
}

\author{
John B. Stokes \\ Department of Internal Medicine, University of lowa Carver College of Medicine and the VA Medical Center, \\ lowa City, lowa, USA
}

\section{Key Words}

Peritoneal dialysis • Hemodialysis • End-stage renal disease • Survival

\begin{abstract}
After initial reports suggesting that patients initiating peritoneal dialysis (PD) had better survival than patients on conventional dialysis in the first year, many investigators have scrutinized the existing databases to determine the reasons for this apparent difference. It is clear that patients starting on PD are selected - they are younger and have less comorbidity compared to the general population on dialysis. Despite improvements in the morbidities of patients on PD over the past 15 years, the survival of patients on hemodialysis over 5 years is greater than for patients on hemodialysis. The latest analysis points to the considerable survival difference in patients who start dialysis with an arteriovenous fistula or graft compared to patients who start dialysis with a cuffed catheter. Thus, the apparent early survival advantage for patients starting PD can be attributed to selection and comorbidities. Data are emerging that the best survival occurs when patients are dialyzed more frequently than the conventional three times a week. The questions regarding dialysis modality now can shift from whether to encourage PD to how to encourage frequent hemodialysis.
\end{abstract}

Copyright $\odot 2012$ S. Karger AG, Base
(C) 2012 S. Karger AG, Basel

0253-5068/12/0333-0160\$38.00/0

Fax +4161306 1234 E-Mail karger@karger.ch www.karger.com www.karger.com/bpu
According to the latest USRDS data (2009), 373,129 patients receive dialysis therapy in the United States. Of these, 25,979 , or less than $7 \%$, receive peritoneal dialysis (PD). Interestingly, only 3,826 , or $1 \%$, receive home hemodialysis [1]. In contrast, there were 165,639 patients with a functioning transplanted kidney. There has been considerable scrutiny of the comparative effectiveness of PD and hemodialysis over the past several years. Several groups have concluded that PD offers a survival advantage over hemodialysis, especially in the first few years [2], and that the loss of residual renal function is slower in patients using PD [3]. The scrutiny of these modalities has increased to the point where we can now be much more confident about our conclusions. The major conclusion given the existing data to date is that there is no major survival benefit to $\mathrm{PD}$ when the complicating and confounding variables are considered.

\section{Randomized Trial of PD and Hemodialysis}

The ultimate test for any set of therapies is a randomized trial. Such a trial was attempted about 10 years ago by the Netherlands Cooperative Study on the Adequacy of Dialysis (NECOSAD) [4]. The aim of the study was to determine the noninferiority of PD in terms of quality of life (QOL). The target enrollment was 100 patients to reach this endpoint, a number too small to assess mortal- 
ity. In order to show a difference of $20 \%$ mortality, the enrollment would need to be about 1,000 patients. Despite a vigorous recruitment effort, these investigators were able to enroll only 38 patients and the study was terminated without adequate power to assess QOL. It is safe to say that there will never be a randomized trial of PD and hemodialysis with mortality as an endpoint.

Given the difficulties in conducting a randomized trial, we are left with having to assess the effectiveness of these therapies by using retrospective analyses. Fortunately, we have a rich and extensive database from which to conduct such analyses - the USRDS.

\section{Consideration of Outcomes in Comparing PD and Hemodialysis}

Clearly, the most important outcome in comparing these modalities is overall mortality. However, as dominant as this outcome is, there are others that deserve consideration. Probably the second most important is overall QOL. Compared to mortality, over which there is no debate about the determination, assessment of QOL is considerably more difficult as it is fundamentally a subjective evaluation and is subject to numerous influences that can vary over short time intervals. Nevertheless, QOL in patients with end-stage renal disease (ESRD) is a particularly important outcome since this disease imposes an enormous patient and family burden.

Other considerations in comparing these two treatment options include hospitalization rates, maintenance of residual renal function, frequency of access intervention, rate of serious infection, cost to the patient, overall costs, and ability to control fluid volume, blood pressure, and consequent heart failure. In addition, special circumstances can be assessed, such as patients with heart failure, hypoalbuminemia, subsequent success of a kidney transplant, and the likelihood of surviving a severe illness.

\section{Morbidity and Mortality Data from the USRDS}

Morbidity is probably best quantitated by analyzing hospitalization rates. In this regard, the rates of hospitalization for hemodialysis patients have remained fairly constant since 1993 at about two admissions per year per patient [1]. The hospitalization rate for PD patients has fallen slightly over the past 15 years, and is now slightly lower than the rate for hemodialysis patients. However, the number of hospital days per year is the same for PD patients as hemodialysis patients, despite the fact that the length of stay for PD patients now is shorter than it was 15 years ago. From this data, we can conclude that there is minimal, if any, difference in hospitalization rates in patients on PD versus those on hemodialysis.

In contrast to the minimal change in hospitalization rates, the causes for hospitalization in dialysis patients have changed dramatically over the past 15 years. Admissions for vascular access for hemodialysis patients have fallen by $45 \%$ while admissions for infection have increased by a comparable amount. For patients on PD, admissions for catheter malfunction have fallen $23 \%$ while admissions for infection have increased 7.5\%. Admissions for cardiovascular diseases have fallen modestly in both groups over the years 2004-2008.

Considerably more attention has been directed at differences in mortality for patients using these two modalities. Figure 1 shows the USRDS data for survival by modality in two different time periods. Several striking facts are immediately apparent. First, the adjusted survival for patients receiving a transplant is more than two times better than any form of dialysis. Second, the mode of dialysis seems to have little effect on survival. Nephrologists know all too well that the 5 -year survival on any form of dialysis averages only 34\%. Data taken from 1999 to 2003 show a slightly different picture. The overall 5-year mortality for dialysis patients has improved by a modest amount. In addition, the survival for patients on PD in the first few years appears to have improved. This 'bump' in the survival curve for PD patients has prompted extensive analysis in order to gain insight into possible reasons for any improvement in mortality for dialysis patients.

The USRDS conducted its own analysis of the survival of patients on PD in their 2010 report. The 1-year survival for PD patients was approximately $87 \%$. As expected, patients with diabetes had greater mortality rates than those on PD without diabetes. When the PD patients were matched with patients on hemodialysis (for age, gender, race, and comorbidities), the 1-year survival probability was similar. This analysis points to the fact that patients undergoing PD are somewhat selected compared to the total population on hemodialysis.

\section{Analyses Using Different Approaches to Large Databases}

A more detailed analysis of the ESRD population was conducted by Mehrotra et al. [5]. They found, using marginal structural models and censoring weighting, that the 
Fig. 1. ESRD adjusted 5-year survival by modality. $\mathrm{Tx}=$ Transplant $\mathrm{HD}=$ hemodialysis. Survival in the later years (right panel) shows improvement in all modalities. In addition, there appears to be modestly increased survival for patients on PD in the first year. Figure reproduced from the USRDS 2010 report [1].

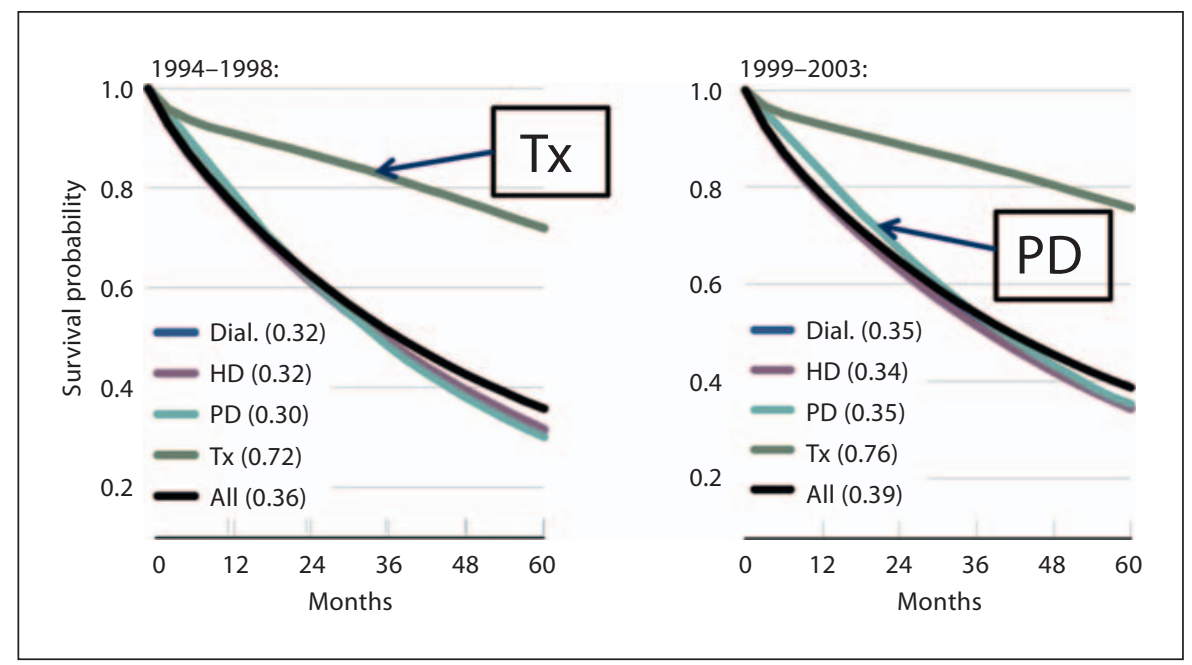

mortality of patients on PD was 7-8\% greater than those on hemodialysis in the late 1990s, a difference that was highly significant. In contrast, the mortality of PD patients from 2002 to 2004 was not different from the mortality of patients on hemodialysis. Thus, it appears that patients on PD have had a relative improvement in their mortality over the past 15-20 years. The group with the greatest improvement in survival were those younger than 65 without diabetes.

The results of the Mehrotra analysis are generally similar to the survival comparisons between PD and hemodialysis for patients in Australia and New Zealand [6]. Patients on PD in those countries have a better survival than hemodialysis patients in the first year, but a somewhat lower survival after several years. Like ESRD patients in the US, patients in Australia and New Zealand undergoing PD appear to have experienced relatively better overall survival over the past 15-20 years. These results are similar to other analyses conducted in other sites using comparable approaches $[7,8]$.

\section{Do Patients on PD Have Better Survival than Patients on Hemodialysis in the First Year?}

Intrigued by the consistent differences in survival in the first year between patients on PD versus those on hemodialysis, Perl et al. [9] hypothesized that some of the differences in early mortality might relate to the methods used in preparing patients for dialysis. Using data from Canadian Organ Replacement Register (CORR), they examined the survival differences between patients starting PD versus those starting hemodialysis with an arteriovenous (AV) fistula or graft. Comparing unadjusted data, they observed that those starting dialysis with a cuffed catheter have a lower survival rate at all time points, and that the major increase in 5-year mortality occurs in the first year. When the data were adjusted for age, race, gender, comorbidity, serum albumin, primary diagnosis, and late referral, the patients who started hemodialysis with an AV fistula or graft had better survival at 5 years. Separation of the two groups became clear at 2 years.

These results add considerable illumination to the puzzling question of why PD patients appear to have superior survival in the first year of dialysis when compared to all patients starting hemodialysis. They vividly illustrate the point that patients who are well prepared for dialysis - whether PD or hemodialysis - will have better survival than patients who are less well prepared and start dialysis with a catheter.

\section{Differences between Patients Who Start Dialysis with a Catheter versus Those Who Start with PD or AV Access}

The CORR data allow us insight into the differences between patients who are well prepared for dialysis (PD or AV fistula) and those who start with a catheter and presumably are less well prepared. Almost two thirds of all patients starting dialysis do so with a catheter [9]. Nephrologists in the United States will probably not be surprised by this data, but given the subsequent outcome 
Table 1. Special conditions favoring PD or hemodialysis using survival as outcome

\begin{tabular}{llll}
\hline Condition & $\begin{array}{l}\text { Favors } \\
\text { PD }\end{array}$ & $\begin{array}{l}\text { Favors } \\
\text { HD }\end{array}$ & $\begin{array}{l}\text { No dif- } \\
\text { ference }\end{array}$ \\
\hline Congestive heart failure & X & 10 \\
\hline Hypoalbuminemia & X & 11 \\
\hline Success of subsequent transplant & & X & 12,13 \\
\hline Survival of severe illness (ICU) & X & & 14 \\
\hline Preservation of renal function & & X & 15 \\
\hline
\end{tabular}

analysis, it should give us great pause. The major reason for this situation is that most patients are referred to a nephrologist too late to begin dialysis with a fistula.

Patients who start dialysis with a catheter are also more likely to have serious comorbidities. Such patients are more likely to have malignancy, lung disease, pulmonary edema, hypoalbuminemia, anemia, and coronary artery disease. However, they are not more likely to have diabetes [9]. These data suggest that patients who have higher mortality on hemodialysis (starting with a cuffed catheter) are generally sicker and have received less medical attention for their renal failure and its consequences before starting dialysis. The differences in survival during the first year or two on dialysis are much less dependent on the modality than on the preparation for dialysis and the avoidance of a cuffed catheter.

\section{Special Considerations for Recommending PD or Hemodialysis}

Thus far, the analysis of whether PD or hemodialysis has an advantage has been directed at all patients with subgroup analysis directed at major categories of patients. However, some investigators have analyzed more specific medical situations to determine whether one or the other modality offers some advantages. As shown in table 1, neither PD nor hemodialysis had any advantage in preserving renal function or in ensuring success of a subsequent kidney transplant.

In contrast, patients who have congestive heart failure or hypoalbuminemia appear to have better survival on hemodialysis $[10,11]$. In addition, patients on hemodialysis appear to survive a severe illness with greater frequency than do patients on PD, although having an AV fistula is associated with better survival than having a catheter [14]. Thus, on close examination of the literature, there is no evidence that PD offers a significant advantage over hemodialysis, even in subgroups that have been examined thus far.

\section{Presenting the Choices for Dialysis Therapy to the Patient}

There is some evidence that many patients do not feel that they are adequately informed of the options and benefits of different forms of ESRD therapy. A rational approach to advising patients on their choices can be approached in the following fashion. The most effective therapy is kidney transplant. The survival of patients who receive a transplant is twice that of patients who are eligible but who cannot get one [16]. Likewise, a patient's QOL with a transplant is superior to those on dialysis. But what about dialysis modalities for those who cannot get a transplant?

Recently, Pauly et al. [17] analyzed the survival of patients who received nocturnal dialysis 5-6 times per week and compared them with matched patients who received a kidney transplant. The mortality of patients on nocturnal dialysis was similar to those who received a kidney from a deceased donor. As expected, these groups have a slightly lower survival than patients who receive a kidney from a living donor. These striking results are unlikely to be an artifact of selection or superiority of Canadian treatment schemes. The nocturnal dialysis patients had significantly greater comorbidities than the transplant patients. Furthermore, the actual survival rates (approx. $80 \%$ at 8 years) reported by Pauly and colleagues for patients on nocturnal dialysis is similar to that recently reported by Lockridge and Kjellstrand [18] in a population from Virginia.

We now can present to patients therapeutic options for ESRD that are solidly based on outcomes, and the decision by the patient and his family can now be made based on issues related to preference and practicality. The newest set of observations relating to a patient's choice is the likelihood that survival on nocturnal dialysis is superior to conventional dialysis. The results of the recently published Frequent Hemodialysis Network (FHN) Trial [19, 20] together with retrospective analyses of frequent (daily) dialysis [21-23] suggest that many patients will benefit from more intensive hemodialysis therapy. At the present time, such therapies can be best administered in the home.

A firm conclusion regarding the generalizability that frequent dialysis (either short daily or nocturnal) is supe- 
rior therapy to conventional dialysis must be subjected to more detailed analysis and carefully designed trials. We do not know the characteristics of the patients who benefit maximally, and we do not know the optimal dialysis dose. While we might presume that more dialysis is better, we need to be alert to possible adverse effects. For example in the FHN trials, frequent dialysis was associated with more frequent revision of vascular access. Despite the possibility that frequent dialysis might pose an unacceptable burden to patients, the results of the daily dialysis trial showed that patients treated more intensively felt better and thought they functioned better than patients treated with conventional dialysis. We are entering an exciting era in dialysis therapy. When we emerge from this era, we should have a much clearer idea of what kinds of therapy are best for which patients.

\section{References}

1 USRDS 2010 Annual Data Report: US Renal Data Systems. Bethesda, National Institutes of Health, National Institute of Diabetes and Digestive and Kidney Diseases, 2010.

- 2 Weinhandl ED, Foley RN, Gilbertson DT, Arneson TJ, Snyder JJ, Collins AJ: Propensity-matched mortality comparison of incident hemodialysis and peritoneal dialysis patients. J Am Soc Nephrol 2010;21:499-506.

- 3 Moist LM, Port FK, Orzol SM, Young EW, Ostbye T, Wolfe RA, Hulbert-Shearon T, Jones CA and Bloembergen WE: Predictors of loss of residual renal function among new dialysis patients. J Am Soc Nephrol 2000;11: 556-564.

-4 Korevaar JC, Feith GW, Dekker FW, van Manen JG, Boeschoten EW, Bossuyt PM, Krediet RT: Effect of starting with hemodialysis compared with peritoneal dialysis in patients new on dialysis treatment: a randomized controlled trial. Kidney Int 2003; 64:2222-2228.

5 Mehrotra R, Chiu YW, Kalantar-Zadeh K, Bargman J, Vonesh E: Similar outcomes with hemodialysis and peritoneal dialysis in patients with end-stage renal disease. Arch Intern Med 2011;171:110-118.

-6 McDonald SP, Marshall MR, Johnson DW, Polkinghorne KR: Relationship between dialysis modality and mortality. J Am Soc Nephrol 2009;20:155-163.

7 Liem YS, Wong JB, Hunink MG, de Charro FT, Winkelmayer WC: Comparison of hemodialysis and peritoneal dialysis survival in The Netherlands. Kidney Int 2007;71:153158.

8 Weinhandl ED, Foley RN, Gilbertson DT, Arneson TJ, Snyder JJ, Collins AJ: Propensity-matched mortality comparison of incident hemodialysis and peritoneal dialysis patients. J Am Soc Nephrol 2010;21:499-506.

-9 Perl J, Wald R, McFarlane P, Bargman JM, Vonesh E, Na Y, Jassal SV, Moist L: Hemodialysis vascular access modifies the association between dialysis modality and survival. J Am Soc Nephrol 2011;22:1113-1121.
10 Sens F, Schott-Pethelaz AM, Labeeuw M, Colin C, Villar E: Survival advantage of hemodialysis relative to peritoneal dialysis in patients with end-stage renal disease and congestive heart failure. Kidney Int 2011, Epub ahead of print.

11 Mehrotra R, Duong U, Jiwakanon S, Kovesdy CP, Moran J, Kopple JD, Kalantar-Zadeh K: Serum albumin as a predictor of mortality in peritoneal dialysis: comparisons with hemodialysis. Am J Kidney Dis 2011;58:418-428.

12 Freitas C, Fructuoso M, Martins LS, Almeida M, Pedroso S, Dias L, Henriques AC, Cabrita A: Posttransplant outcomes of peritoneal dialysis versus hemodialysis patients. Transplant Proc 2001;43:113-116.

13 Perl J, Hasan O, Bargman JM, Jiang D, Na Y, Gill JS, Jassal SV: Impact of dialysis modality on survival after kidney transplant failure. Clin J Am Soc Nephrol 2011;6:582-590.

14 Sood MM, Miller L, Komenda P, Reslerova M, Bueti J, Santhianathan C, Roberts D, Mojica J, Rigatto C: Long-term outcomes of endstage renal disease patients admitted to the ICU. Nephrol Dial Transplant 2011;26:29652970.

15 van der Wal WM, Noordzij M, Dekker FW, Boeschoten EW, Krediet RT, Korevaar JC, Geskus RB, The Netherlands Cooperative Study on the Adequacy of Dialysis Study Group (NECOSAD): Full loss of residual renal function causes higher mortality in dialysis patients; findings from a marginal structural model. Nephrol Dial Transplant 2011;26:2978-2983.

16 Wolfe RA, Ashby VB, Milford EL, Ojo AO, Ettenger RE, Agodoa LYC, Held PJ, Port FK: Comparison of mortality in all patients on dialysis, patients on dialysis awaiting transplantation, and recipients of a first cadaveric transplant. N Engl J Med 1999;341:17251730.
17 Pauly RP, Gill JS, Rose CL, Asad RA, Chery A, Pierratos A, Chan CT: Survival among nocturnal home haemodialysis patients compared to kidney transplant recipients. Nephrol Dial Transplant 2009;24:2915-2919.

18 Lockridge RS, Kjellstrand CM: Nightly home hemodialysis: outcome and factors associated with survival. Hemodial Int 2011; 15:211-218.

19 Chertow GM, Levin NW, Beck GJ, Depner TA, Eggers PW, Gassman JJ, Gorodetskaya I, Greene T, James S, Larive B, Lindsay RM, Mehta RL, Miller B, Ornt DB, Rajagopalan S, Rastogi A, Rocco MV, Schiller B, Sergeyeva O, Schulman G, Ting GO, Unruh ML, Star RA, Kliger AS: In-center hemodialysis six times per week versus three times per week. N Engl J Med 2010;363:2287-2300.

20 Rocco MV, Lockridge RS, Beck GJ, Eggers PW, Gassman JJ, Greene T, Larive B, Chan CT, Chertow GM, Copland M, Hoy CD, Lindsay RM, Levin NW, Ornt DB, Pierratos A, Pipkin MF, Rajagopalan S, Stokes JB, Unruh ML, Star RA, Kliger AS: The effects of frequent nocturnal home hemodialysis: the Frequent Hemodialysis Network Nocturnal Trial. Kidney Int 2011, E-pub ahead of print.

21 Johansen KL, Zhang R, Huang Y, Chen SC, Blagg CR, Goldfarb-Rumyantzev AS, Hoy CD, Lockridge RSJ, Miller BW, Eggers PW, Kutner NG: Survival and hospitalization among patients using nocturnal and short daily compared to conventional hemodialysis: a USRDS study. Kidney Int 2009;76:984-990.

22 Kjellstrand C, Buoncristiani U, Ting G, Traeger J, Piccoli GB, Sibai-Galland R, Young BA, Blagg CR: Survival with shortdaily hemodialysis: association of time, site, and dose of dialysis. Hemodial Int 2010;14: 464-470.

23 Kjellstrand CM, Buoncristiani U, Ting G, Traeger J, Piccoli GB, Sibai-Galland R, Young BA, Blagg CR: Short daily haemodialysis: survival in 415 patients treated for 1006 patient-years. Nephrol Dial Transplant 2008;23:3283-3289. 